\title{
Renal graft dysfunction during infection with cytomegalovirus: association with IgM lymphocytotoxins and HLA-DR3 and DR7
}

\author{
W M BALDWIN III, F H J ClAAS, A vaN ES, W L WESTEDT, G vaN GEMERT, M R DAHA, \\ L A VAN ES
}

\begin{abstract}
Of 121 consecutive adult recipients of cadaver renal transplants who were treated with low dose steroids and azathioprine, 23 developed active cytomegalovirus infections. These 23 patients were divided into three groups on the basis of their symptoms related to the infection: five patients had no renal, respiratory, or haematological abnormalities; seven had renal dysfunction; and nine had renal dysfunction plus respiratory or haematological abnormalities. Two patients were regarded as a separate group because their infections occurred two to four weeks after graft nephrectomy.
\end{abstract}

All but three of the patients produced IgM or IgG lymphocytotoxins during their infections. In the patients with mild infections and in control patients without infections, however, these lymphocytotoxins were predominantly IgG antibodies that were not precipitated by $3.5 \%$ macrogol (polyethylene glycol). In contrast, 12 of the 16 patients with renal dysfunction during their infections had broadly reactive IgM lymphocytotoxins. These IgM lymphocytotoxins lysed $T$ as well as $B$ lymphocytes at $22^{\circ} \mathrm{C}$ and were precipitated by $3.5 \%$ macrogol, suggesting that they were circulating as immune complexes. Rheumatoid factors were found in sera from nine patients with cytomegalovirus infections, seven of whom developed leukopenia or pneumonia, or both, in addition to renal dysfunction.

Some of these immune responses associated with cytomegalovirus infection in transplant recipients may be genetically controlled since 10 of 11 patients positive for HLA-DR3 or DR7 produced IgM lymphocytotoxins.

\section{Introduction}

Cytomegalovirus infections are a major cause of morbidity in transplant recipients. Fever, leukopenia, thrombocytopenia, pneumonia, liver dysfunction, and renal dysfunction have been associated with such infections. ${ }^{1-5}$ The pathogenesis of these various manifestations has not been fully clarified. During cytomegalovirus infection, however, immune complexes have been detected in the circulation and granular deposits of immunoglobulins shown in the glomeruli of patients with and without renal transplants, ${ }^{5-9}$ suggesting that renal dysfunction may be caused by immune complexes. Yet many patients with cytomegalovirus infections and circulating immune complexes

University Hospital, 2333 AA Leiden, The Netherlands

W M BALDWIN III, MD, PHD, research associate, nephrology department

F H J CLAAS, BSC, head of screening laboratory, immunohaematology department

A vAN ES, MD, consultant in internal medicine, nephrology department W L WESTEDT, MD, research fellow, rheumatology department

G vAN GEMERT, MSC, head of serology laboratory, virology department

M R DAHA, PHD, head of research laboratory, nephrology department

L A VAN ES, MD, PHD, professor and chairman, nephrology department do not develop renal dysfunction, and in all but one case cytomegalovirus antigens have not been shown in the glomerular deposits. ${ }^{7}$ Many of the antibodies generated during cytomegalovirus infections are directed to autoantigens such as DNA, smooth muscle, IgG (rheumatoid factor), lymphocytes, and erythrocytes. ${ }^{8-11}$

We undertook the present investigation to determine whether certain autoantibodies induced by cytomegalovirus may circulate as immune complexes and cause renal damage.

\section{Patients and methods}

\section{PATIENTS}

We studied all 23 adults who developed well documented primary or secondary cytomegalovirus infections in the first four months after cadaver renal transplantation at this hospital between January 1980 and January 1983. Eight patients with primary infections and eight with secondary infections experienced renal dysfunction during their infections. An additional 15 patients without active cytomegalovirus infections who experienced renal graft dysfunction during the same period were studied as controls for antibody responses related solely to rejection of the transplant. All 121 adults who received cadaver renal transplants at this hospital during the study period were treated with low dose steroids and azathioprine ${ }^{12}$ and followed up by one team of physicians.

\section{METHODS}

Serum samples were obtained weekly from each patient after transplantation. In the case of patients with active cytomegalovirus infections samples were selected from the time when titres of antibodies to cytomegalovirus increased and renal dysfunction or other symptoms were recorded. Additional samples obtained before and after the active infections were tested for longitudinal studies. In the case of control patients, who experienced acute rejection but did not have cytomegalovirus infections, samples were selected from those obtained within a week after removal of the transplant to maximise the chances of finding lymphocytotoxins in the circulation.

Macrogol (polyethylene glycol) 6000 precipitates were prepared by incubating $0.5 \mathrm{ml}$ serum with $0.5 \mathrm{ml}$ phosphate buffered saline $(0.07$ mol sodium chloride and $0.001 \mathrm{~mol}$ phosphate buffer) containing $35 \mathrm{mg}$ macrogol at $0^{\circ} \mathrm{C}$ for one hour. These samples were centrifuged at $2000 \mathrm{~g}$ for 15 minutes at $4{ }^{\circ} \mathrm{C}$. The supernatant was saved and the precipitate dissolved in $0.5 \mathrm{ml}$ phosphate buffered saline.

Assays-The following standard determinations were performed on the macrogol precipitates and supernatants: a Folin determination for total protein content; an immunodiffusion assay for IgM immunoglobulin concentration; latex agglutination for rheumatoid factor; and the National Institutes of Health complement dependent cytotoxicity assay performed at $22^{\circ} \mathrm{C}$ on peripheral blood lymphocytes from a panel of 10 donors for lymphocytotoxins. The classes of the lymphocyte reactive antibodies and rheumatoid factors were determined by indirect immunofluorescence with heavy chain specific antibodies. ${ }^{13}$ All HLA typing of graft recipients had been routinely performed by Eurotransplant in Leiden before transplantation. Titres of antibodies to cytomegalovirus were determined by a standard immune adherence haemagglutination technique. ${ }^{14}$ Titres of less than 8 were considered to be negative. A diagnosis of active cytomegalovirus infection was based on a fourfold or greater increase in the titre of antibodies to cytomegalovirus or on culture of cytomegalovirus from urine, blood, or sputum. 


\section{Results}

The 23 patients who developed active cytomegalovirus infections after cadaver renal transplantation were divided into four groups on the basis of renal, respiratory, and haematological findings. Five patients had no detectable renal, respiratory, or haematological abnormalities (group 1); seven patients had renal dysfunction as evidenced by otherwise unexplainable increases in serum creatinine concentration (>50 mmol/1 $(>566 \mathrm{mg} / 100 \mathrm{ml})$ ) or proteinuria $(1.3-8.0 \mathrm{~g} /$ day) (group 2); and nine patients had leukopenia $(<2 \times$ $\left.10^{9} \mathrm{cells} / \mathrm{l}\right)$, thrombocytopenia $\left(<100 \times 10^{8} \mathrm{cells} / \mathrm{l}\right)$, or radiological evidence of respiratory infections in addition to renal dysfunction (group 3). Two patients were considered separately (group 4) because they developed cytomegalovirus infections two and four weeks after irreversible graft rejections.

Six of the 12 patients in groups 1 and 2 and all of the patients in groups 3 and 4 were febrile. Five of the patients in groups 1 and 2 and two in group 3 had raised transaminase activities during their infections. Titres of antibodies to cytomegalovirus were inversely correlated with the severity of symptoms: patients with mild symptoms had higher titres (geometric mean titre $>512$ in group 1) than patients with more severe symptoms (geometric mean titre 256 in group 2 and 128 in groups 3 and 4 ). This may reflect in part the debilitating effects of the infections in patients in group 3, since four of these patients had considerable leukopenia, eight had respiratory infections, and three died of causes related to the cytomegalovirus infection. No significant differences were observed between the four groups of patients in the distribution of primary and secondary infections (12:11), age (38 (SD 11) years), or sex (13 men:10 women).

Although the amount of material similar to IgM immune complexes that was precipitated by $3.5^{\circ}$, macrogol was raised in all four groups of patients with active cytomegalovirus infections $(35(6) \% v 15.4$ (4) $\%$ in transplant recipients without such infections $\left.{ }^{8}\right)$, the reactivity of the IgM antibodies contained in the precipitate varied. Macrogol precipitated lymphocytotoxins in only one of the five patients without renal dysfunction (group 1) but in 12 of the 16 patients with renal dysfunction (table I; p $<0.05$ by $\%^{2}$ analysis). Seven of the nine patients with pneumonia or leukopenia, or both, in addition to renal dysfunction (group 3) had rheumatoid factor that was precipitated by macrogol (mean titre 640), whereas only two of the 12 patients in groups 1 and 2 had circulating rheumatoid factors, with titres of 240 and 320 . Longitudinal studies showed that the appearance of rheumatoid factors and lymphocytotoxins precipitated by macrogol coincided with the clinical findings of renal dysfunction, whereas the non-precipitable lymphocytotoxins did not. The rheumatoid factors were predominantly IgM with only minor amounts of IgG and IgA. The antibodies that were precipitated by macrogol were shown to be IgM when the lymphocytotoxin test was performed on ultracentrifuged fractions of the patients' sera and when lymphocytes were stained with the patients' sera and specific anti-IgM or IgG labelled with fluorescein. In contrast, the non-precipitable lymphocytotoxins were $7 \mathrm{~S} \mathrm{IgG} \mathrm{antibodies.} \mathrm{Both} \mathrm{types} \mathrm{of} \mathrm{lympho-}$ cytotoxins usually lysed cells from $50-100 \%$ of the donor panel. The antibodies precipitated by macrogol lysed $\mathrm{T}$ as well as $\mathrm{B}$ lymphocytes, and their reactivity did not correlate with the HLA antigens of the cell donors.

Sera from 15 patients who received renal transplants at Leiden during the same period and had renal dysfunction due to irreversible acute rejection in the absence of active cytomegalovirus infections were tested in the same assays. These patients were similar to the patients with renal dysfunction associated with infection in age (38 (12) years), sex (10 men:5 women), and titres of antibodies to cytomegalovirus before transplantation (seven without detectable antibodies and eight with antibodies). Rejection was not accompanied by production of rheumatoid factor in any of these 15 patients. Cicciarelli et $a l^{15}$ also reported that renal graft rejection is not associated with production of rheumatoid factor. Only two of these control patients developed lymphocytotoxins precipitable by macrogol, which reacted weakly with $10-20 \%$ of the lymphocyte panel; eight of these 15 patients had IgG lymphocytoxins not precipitable by macrogol at the time of graft rejection (table I).

As the tendency to form certain antibodies may be linked to immune response genes (HLA-DR) the HLA type of each group of patients was analysed. The prevalence of HLA-DR types in the patients with cytomegalovirus infections did not differ significantly from that in the total population of 121 adults who received cadaver renal transplants at Leiden during the study period. Ten of the 11 patients positive for HLA-DR3 or DR7 who developed active cytomegalovirus infections, however, produced IgM lymphocytotoxins that were precipitated by macrogol (table II). In addition, the two patients who produced weak IgM lymphocytoxins that were precipitable by macrogol in the absence of active infections were also positive for DR3 or DR7. The incidence as well as the intensity of the lymphocytotoxin response was increased by cytomegalovirus infection in the patients positive for DR3 and DR7 because seven patients in the control group without infections who were positive for DR3 or DR7 did not produce detectable IgM lymphocytotoxins that were precipitable by macrogol (table II).

TABLE I-Laboratory findings in renal transplant recipients* with active cytomegalovirus infections (figures are numbers of patients)

\begin{tabular}{lccccc}
\hline & $\begin{array}{c}\text { Group 1 } \\
(\mathrm{n}=5)\end{array}$ & $\begin{array}{c}\text { Group 2 } \\
(\mathrm{n}=7)\end{array}$ & $\begin{array}{c}\text { Group 3 } \\
(\mathrm{n}=9)\end{array}$ & $\begin{array}{c}\text { Group 4 } \\
(\mathrm{n}=2)\end{array}$ & $\begin{array}{c}\text { Controls } \\
(\mathrm{n}=15)\end{array}$ \\
\hline $\begin{array}{l}\text { Primary: secondary } \\
\text { infection }\end{array}$ & $3: 2$ & $3: 4$ & $5: 4$ & $1: 1$ & $0: 0$ \\
$\begin{array}{c}\text { Lymphocytotoxins in: } \\
\text { Whole serum }\end{array}$ & 3 & 7 & 9 & 2 & 10 \\
$\begin{array}{c}\text { Macrogol supernatant } \\
\text { (IgG) }\end{array}$ & 2 & 2 & 7 & 1 & 8 \\
$\begin{array}{c}\text { Macrogol precipitate } \\
\text { (IgM) }\end{array}$ & 1 & 6 & 6 & 2 & 2 \\
Rheumatoid factor (IgM) & 1 & 1 & 7 & 0 & 0 \\
\hline
\end{tabular}

* Group $1=$ patients without renal, respiratory, or haematological abnormalities during their infection. Group $2=$ patients with renal dysfunction. Group $3=$ patient with renal dysfunction and respiratory or haematological abnormalities. Group $4=$ patients who developed cytomegalovirus infections after graft rejection.
patients with graft rejection without active cytomegalovirus infections.

TABLE II-Association of IgM lymphocytotoxins precipitable by macrogol with HLA-DR3 or DR7 in renal transplant recipients

\begin{tabular}{|c|c|c|c|}
\hline \multirow{2}{*}{$\begin{array}{l}\text { HLA-DR } \\
\text { or DR7 }\end{array}$} & \multicolumn{2}{|c|}{$\begin{array}{l}\text { Lymphocytotoxins } \\
\text { precipitable by macrogol }\end{array}$} & \multirow{2}{*}{ Significance } \\
\hline & Present & Absent & \\
\hline \multicolumn{4}{|c|}{ Patients with cytomegalovirus infections } \\
\hline $\begin{array}{l}\text { Present } \\
\text { Absent }\end{array}$ & $\begin{array}{r}10 \\
5\end{array}$ & $\frac{1}{7}$ & $\mathrm{p}<0.05$ \\
\hline \multicolumn{4}{|c|}{ Patients without cytomegalovirus infections } \\
\hline $\begin{array}{l}\text { Present } \\
\text { Absent }\end{array}$ & $\begin{array}{l}2 \\
0\end{array}$ & $\begin{array}{l}7 \\
6\end{array}$ & NS \\
\hline
\end{tabular}

NS $=$ Not significant

\section{Discussion}

Active cytomegalovirus infections were documented in 23 of 121 adult recipients of cadaver renal transplants. This low incidence of infection is probably related to the low dosage of steroids used for immunosuppression in our patients. Others have reported that the incidence of such infections decreases with decreased immunosuppressive treatment. ${ }^{16} 17$ None the less, 16 of our patients developed renal dysfunction and nine developed leukopenia, thrombocytopenia, or respiratory infections in addition to renal dysfunction.

As both the susceptibility to and the symptoms from murine cytomegalovirus infection are linked to the major histocompatibility locus in mice ${ }^{1819}$ we searched for such a linkage in our patients. No genetic predisposition to active cytomegalovirus infections was discerned in our patients. Some of the immune responses to the infection, however, appeared to be linked to certain HLA-DR genes. During active cytomegalovirus infections 10 of the 11 patients who were positive for DR3 or DR7 formed broadly reactive IgM lymphocytotoxins, and eight of these patients developed renal dysfunction which coincided with the appearance of these antibodies and was associated with heavy granular deposits of IgM in the glomeruli. ${ }^{5}{ }^{8}$ In one patient this IgM response persisted for over eight months after graft nephrectomy and the end of immunosuppressive treatment, suggesting that neither foreign histocompatibility antigens nor immunosuppression were required to maintain this response. Another patient, who was positive for DR3 and developed an active cytomegalovirus infection one month 
after removal of the transplant, also produced a strong IgM lymphocytotoxin response in the absence of foreign histocompatibility antigens and immunosuppressive treatment. Finally, one patient positive for DR3 and one positive for DR7, who rejected their kidneys in the absence of demonstrable cytomegalovirus infections, developed weak IgM lymphocytotoxin responses, while 13 other patients undergoing acute graft rejections did not (table II). These observations emphasise the contribution of genetic factors to the $\operatorname{IgM}$ lymphocytotoxin response in our patients. Other investigators have reported that normal subjects and patients with autoimmune diseases who are positive for DR3 produce increased amounts of certain antibodies and clear immune complexes from their circulation at decreased rates. ${ }^{20-22}$

The IgM lymphocytotoxins in our patients may have been circulating in the form of immune complexes as they were precipitated by $3.5 \%$ macrogol and this procedure preferentially precipitates material that is similar to immune complexes from serum. ${ }^{8}$ In eight patients the precipitate contained only $37(8) \%$ of the total IgM in the sera but all of the lymphocytoxic activity. These lymphocytotoxins do not appear to be directed to HLA antigens as there was no correlation between the HLA type of the lymphocytes in the panel and the patterns of lymphocytotoxicity observed. They also were not exclusively "cold B-lymphocytotoxins" 2324 as they reacted strongly with $\mathrm{T}$ lymphocytes at $22^{\circ} \mathrm{C}$. Chalopin and Rifle $\mathrm{e}^{11}$ have also noted that virally induced $\operatorname{IgM}$ antibodies with $\mathrm{T}$ lymphocyte reactivity are associated with renal graft dysfunction.

The nine patients in our study who experienced leukopenia or respiratory infections, or both, in addition to renal graft dysfunction frequently had not only circulating IgM lymphocytotoxins but also IgM rheumatoid factors and IgG lymphocytotoxins. The symptoms of the cytomegalovirus infections did not coincide in time with the appearance of the IgG lymphocytotoxins but they did with the appearance of the rheumatoid factors. In one patient rheumatoid factor and symptoms were present for only two weeks. In the eight other patients rheumatoid factors were present for from three to eight weeks. Although producing the most rheumatoid factors and lymphocytotoxins, this group of patients with severe symptoms related to the cytomegalovirus infection produced the lowest titres of antibodies to cytomegalovirus. The possibility that the production or presence of lymphocytotoxins or rheumatoid factors may inhibit the production or activity of antibodies to cytomegalovirus is currently under investigation.

Our data suggest that although all transplant recipients may have an increased risk of cytomegalovirus infections, certain immune responses to this infection may be linked to HLA-DR genes and these responses may influence the symptoms of the infection. These observations may explain in part the "protean clinical manifestations" ${ }^{25}$ of cytomegalovirus infections.

This work was supported by grant C83 388 from the Dutch Kidney Foundation.

We are grateful to Judy Burgers, Marian Witvliet, and $\mathrm{H} \mathrm{H}$ de Rooij-Dijk, who performed the IgM macrogol, lymphocytotoxicity, and latex fixation assays, and to Mary Mentink, who provided instruction in the use of the word processor.

\section{References}

${ }^{1}$ Betts RF, Freeman RB, Douglas RG, Talley TE. Clinical manifestations of renal allograft derived primary cytomegalovirus infection. $A m \mathcal{F}$ Dis Child 1977;131:759-63.

${ }^{2}$ Filia M, Payne JE, Berne TV, et al. Epidemiology of cytomegalovirus infection after transplantation and immunosuppression. $\mathcal{F}$ Inf $D i s$ $1975 ; 132: 421-33$.

${ }^{3}$ Suwansirikul S, Rao N, Dowling JN, Ho M. Primary and secondary cytomegalovirus infection: clinical manifestations after renal transplantation. Arch Intern Med 1977;137:1026-9.

+ Warrell MJ, Chinn I, Morris PJ, Tobin JO'H. The effects of viral infections on renal transplants and their recipients. $Q \mathcal{F}$ Med $1980 ; \mathbf{4 9}$ : 219-31.
${ }^{5}$ Richardson WP, Colvin RB, Cheesman SH, et al. Glomerulopathy associated with cytomegalovirus viremia in renal allografts. $N$ Engl $\mathcal{Z}$ Med $1981 ; 305: 57-63$.

"Stagno S, Volkanakis JE, Reynolds DW, Stroud R, Alford CA. Immunec complexes in congenital and natal cytomegalovirus infections in man f Clin Invest 1977;60:838-45.

' Ozawa T, Steward JA. Immune-complex glomerulonephritis associated with cytomegalovirus infection. Am f Clin Pathol 1979;72:103-7.

${ }^{*}$ Baldwin WM III, van Es A, Valentijn RM, van Gemert GW, Daha MR van Es LA. Increased IgM and IgM immune complex-like material in the circulation of renal transplant recipients with primary cytoe megalovirus infections. Clin Exp Immunol 1982;50:515-24.

${ }^{9}$ Kantor GL, Goldberg LS, Johnson BL, Derechin MM, Barnett EV $\overrightarrow{\vec{B}}$ Immunologic abnormalities induced by post perfusion cytomegalovirus infection. Ann Intern Med 1970;73:553-8.

${ }^{10}$ Anderson P, Andersen HK. Immunoglobulin levels and specific vira: antibodies in relation to smooth muscle antibodies in cytomegalovirus $\overline{\bar{c}}$ infection. F Clin Lab Immunol 1978;1:233-6.

$"$ Chalopin J-M, Rifle G. Role of cold lymphocytotoxic antibodies (CLA) in human allograft recipients. Transplant Proc 1979;11:1271-3.

12 van Hoeff JP, van Es A, Koolen MI, Kalff MW, van den Broek $\mathrm{PH}_{2}$ de Graeff J. Less aggressive rejection therapy and low-dose corti-○ costeroids leading to satisfactory cadaveric kidney graft survival andlow morbidity rate. Proc Eur Dial Transplant Assoc 1980;17:435-40. $\vec{\omega}$

${ }^{13}$ Valentijn RM, Kauffmann RH, Brutel de la Riviere G, Daha MR, van Es LA. Presence of circulating macromolecular IgA in patients with? hematuria due to primary IgA nephropathy. Am $\mathcal{f}$ Med 1983;74 375-81.

${ }^{14}$ Lennette DA, Lennette ET, Wentworth BB, French MLV, Lattimer GL $\stackrel{\infty}{\text { V }}$ Serology of Legionnaires disease: comparison of indirect fluorescenio antibody, immune adherence hemagglutination, and indirect hemag- $\frac{+}{\mathrm{N}}$
glutination tests. F Clin Microbiol 1979;10:876-9.

${ }^{15}$ Cicciarelli JC, Terasaki PI, Chia D, et al. A simple rapid micro-latexfixation test. Clin Exp Immunol 1979;38:181-5.

${ }^{16}$ Rubin RH, Cosimi AB, Hirsch MS, Herrin JT. Effects of antithymocyte globulin on cytomegalovirus infection in renal transplant recipients음 Transplantation $1981 ; 31: 143-6$.

17 Pass RF, Whitley RJ, Diethelm AG, Whechel JD, Reynolds DW, Alford CA. Cytomegalovirus infection in patients with renal transplants potentiation by antithymocyte globulin and an incompatible graft f Inf Dis 1980;142:9-17.

${ }^{18}$ Chalmer JE. Genetic resistance to MCMV infection. In: Skamene ED ed. Genetic control of natural resistance to infection and malignancy New York: Academic Press, 1980:283-90.

${ }^{19}$ Hudson JB. Murine cytomegalovirus as a model for the study of virabo pathogenesis and persistent infections. Arch Virol 1979;62:1-29.

${ }^{20}$ Lawley TJ, Hall RP, Fauci AS, Katz SI, Hamburger MI, Frank MMO Defective Fc-receptor functions associated with the HLA-B8/DRw30 haplotype. N Engl f Med $1981 ; 304: 185-92$.

21 Ahearn JM, Provost TT, Dorsch CA, Stevens MB, Bias WB, Arnett FC Interrelationships of HLA-DR, MB and MT phenotypes, autoantibod expression, and clinical features in systemic lupus erythematosus Arthritis Rheum 1982;25:1031-40.

22 Legrand L, Rivat-Perran L, Huttin C, Dausset J. HLA- and Gm-linke $\vec{\delta}$ genes affecting the degradation rate of antigens (sheep red cells) endo-3 cytized by macrophages. Hum Immunol 1982;4:1-9.

${ }^{23}$ Cicciarelli JC, Chia D, Terasaki PI, Barnett EV, Shirahama S. IgM㞔 anti-IgM cold lymphocytotoxins to B cells. Transplant Proc 1979;11 1950-3. 24 Jeanet $M$, Stalder $\mathrm{H}$. Lymphocytotoxic antibodies in spontaneous cyto
megalovirus infection. Br Med $\mathcal{F} 1978 ; \mathrm{i}: 509$.

25 Weller TH. The cytomegaloviruses: ubiquitous agents with protear? clinical manifestations. N Engl f Med 1971;285:203-14.

(Accepted 14 fuly 1983)

ONE HUNDRED YEARS AGO A CORRESPONDENT writes $\frac{\text { D }}{\text { O }}$

"Having worn a Spanish sash for some time, many years ago, whils్ walking in the Pyrenees, I am decidedly of opinion that the weight of the trousers is supported much more easily, and pleasantly, by of sash than by braces; these last are narrow, about 2 inches wide, and though custom enables us to wear them without conscious incone venience, I think any one using them for the first time would fin them very unpleasant. The sash worn by the middle and lower class in Aragon is of wool 8 or 9 inches broad, and (if my recollection is correct) about 4.1 feet long; when of such width and length it doe席 not need to be drawn tight, but only closely wrapped round the waist and the end tucked in. I should certainly wear one constantly but that I do not wish to have an eccentric appearance. Medical meno I believe, attach great value to the wearing of sashes or bands round the stomach, especially in hot countries. A narrow silken sash whic must be drawn tight is, I should suppose, far less pleasant to wear. (British Medical fournal 1883;i:1051.) 